\title{
Diagnostic and Prognostic Value of Presepsin in Patients with Non-Infectious Organ Failure, Sepsis, and Septic Shock: A Prospective Observational Study According to the Sepsis-3 Definitions
}

\section{Sukyo Lee}

Korea University Ansan Hospital

Juhyun Song ( $\sim$ songcap97@hotmail.com )

Korea University Ansan Hospital https://orcid.org/0000-0001-6217-7360

Dae Won Park

Korea University Ansan Hospital

Hyeri Seok

Korea University Ansan Hospital

Jae-hyung Cha

Korea University Ansan Hospital

Sejoong Ahn

Korea University Ansan Hospital

Jooyeong Kim

Korea University Ansan Hospital

Jonghak Park

Korea University Ansan Hospital

Han-jin Cho

Korea University Ansan Hospital

Research

Keywords: Presepsin, Sepsis, Septic shock, Organ failure, Infection, Mortality

Posted Date: April 19th, 2021

DOI: https://doi.org/10.21203/rs.3.rs-413686/v1

License: (c) (1) This work is licensed under a Creative Commons Attribution 4.0 International License.

Read Full License 


\section{Abstract}

Background: Sepsis is life-threatening organ dysfunction due to a dysregulated host response to infection. Early diagnosis of sepsis is challenging due to unknown sources of infection, and mortality prediction is usually complex. We aimed to investigate the clinical value of presepsin for discriminating sepsis from non-infectious organ failure and predicting mortality among sepsis patients in the emergency department (ED).

Methods: This prospective observational study included 420 patients divided into three groups according to the Sepsis-3 definitions: non-infectious organ failure $(n=142)$, sepsis $(n=141)$, and septic shock $(n=137)$. Blood samples for biomarker measurement of presepsin, procalcitonin, and C-reactive protein were drawn in the ED and biomarker levels were compared between the groups. Optimal cut-off values for presepsin to discriminate between the three clinical diagnoses were evaluated using receiver operating characteristic (ROC) curve analysis. We also performed ROC curve analysis for each biomarker as a predictor of mortality. After excluding non-infectious organ failure, we extracted the optimal cut-off value of presepsin to predict mortality associated with sepsis and septic shock and performed Kaplan-Meier survival curve analysis according to the cut-off value.

Results: Presepsin levels (median [IQR]) were significantly higher in sepsis than in non-infectious organ failure (792 [450-1273] vs. 286 [170-417], $p<0.001)$ and significantly higher in septic shock than in sepsis (1287 [589-2365] vs. 792 [450-1273], $p=0.002)$. The optimal cut-off value for presepsin to discriminate between sepsis and non-infectious organ failure was $582 \mathrm{pg} / \mathrm{mL}$ (sensitivity, 70.1; specificity, 89.4; AUC, 0.877; $p<0.001$ ) and to discriminate between sepsis and septic shock was $1285 \mathrm{pg} / \mathrm{mL}$ (sensitivity, 50.4; specificity, 76.6; AUC, 0.618; $p$ <0.001). The optimal cut-off value for presepsin for predicting 30-day mortality was $821 \mathrm{pg} / \mathrm{mL}$ (sensitivity, 68.9; specificity, 50.5; AUC, 0.605; $p=0.005$ ) in patients with sepsis and septic shock. Kaplan-Meier survival curve analysis showed that patients with higher presepsin levels ( $\geq 821 \mathrm{pg} / \mathrm{mL}$ ) had significantly higher mortality than patients with lower presepsin levels $(<821 \mathrm{pg} / \mathrm{mL})$ (log-rank test; $\mathrm{p}=0.004)$.

Conclusions: Presepsin levels could effectively differentiate sepsis from non-infectious organ failure and septic shock from sepsis. Presepsin levels could help clinicians predict mortality in patients with sepsis and septic shock.

\section{Background}

Sepsis is defined as a life-threatening organ dysfunction caused by a dysregulated host response to infection [1]. Despite advances in management, sepsis is the leading cause of mortality in critically ill patients [2, 3]. According to the Surviving Sepsis Campaign (SSC) guidelines, to improve survival outcomes, early diagnosis of sepsis and therapeutic interventions are essential [2, 4, 5]. Although the Third International Consensus Definitions for Sepsis and Septic Shock (Sepsis-3) have been developed [1, 6], no single gold standard diagnostic method for sepsis has been identified. Blood culture can help 
determine the presence of bacteremia, but it usually takes a few days to obtain the microbiological results and yields false negative results in many cases. Thus, various novel biomarkers to determine the presence of infection have been evaluated, and some markers, such as C-reactive protein (CRP) and procalcitonin (PCT), are being widely used in clinical settings [7, 8]. Although PCT is known to have higher specificity for bacterial infection than CRP and other traditional markers, its level may also be elevated in conditions without infection [7, 9]. PCT also appears to have a limited capacity for predicting mortality associated with sepsis [10].

The soluble cluster of differentiation 14 subtype, presepsin, was reported to have diagnostic and prognostic capacity in septic patients in some studies performed according to the previous Sepsis-2 definitions [11-13]. Other studies using systemic review and meta-analysis showed that the diagnostic accuracy of presepsin in detecting infection was similar to that of PCT, and both biomarkers were useful for the early diagnosis of sepsis $[14,15]$. A recent study using Sepsis-3 reported that presepsin and PCT were superior to CRP and lactate in discriminating sepsis and septic shock from systemic inflammatory response syndrome (SIRS) without infection [16]. Another study using Sepsis-3 also showed that presepsin could effectively discriminate sepsis without shock from non-septic patients with an increase in sepsis-related organ failure assessment (SOFA) score of 2 or more [17].

However, to our knowledge, there has been no study on the diagnostic and prognostic value of presepsin, including organ failure patients in the emergency department (ED), according to the latest Sepsis-3 definitions. Therefore, we aimed to investigate the diagnostic value of presepsin levels in patients with non-infectious organ failure, sepsis, and septic shock, as well as the prognostic value of presepsin levels in patients with sepsis and septic shock.

\section{Methods}

\section{Study design and setting}

This single-center prospective observational study was performed in the ED of Korea University Ansan Hospital, Korea. Our institution is a 910-bed tertiary care teaching hospital with an annual visit of approximately 50,000 patients in the ED. This study was conducted in accordance with the Declaration of Helsinki and was approved by the Institutional Review Board (IRB) of Korea University Ansan Hospital (IRB no. 2020AS0031). Written informed consent was obtained from all patients or their legal representatives.

\section{Study population}

From July 2019 to August 2020, adults ( $\geq 18$ years) who had a positive quick sepsis-related organ failure assessment (qSOFA) score upon ED presentation were screened for participation. This scoring system uses three criteria: low blood pressure (systolic blood pressure $\leq 100 \mathrm{mmHg}$ ), high respiratory rate ( $\geq 22$ breaths/min), and altered mental status (Glasgow coma score $<15$ ). One point is assigned for each criterion, with the final score ranging from 0 to 3 points. A positive qSOFA score is defined as $\geq 2$ qSOFA 
points. In the present study, another inclusion criterion was an increase in the SOFA score by $\geq 2$ points in the ED, irrespective of the current infection. Since September 2017, our institution has been using the Intelligent Sepsis Management System (i-SMS), a qSOFA alert system, which helps ED clinicians promptly identify sepsis and manage sepsis according to the SSC 2016 guidelines $[4,5]$. The system automatically enrolled patients who had a positive qSOFA score upon ED arrival and assisted in the decision-making process for sepsis management. If the patients had baseline SOFA scores, we used the standard of an increase in SOFA score of at least 2. If the patients had no previous SOFA score, two infectious disease (ID) experts reviewed the medical records with laboratory data and determined the change in SOFA score. Exclusion criteria were refusal to consent, an increase in SOFA score of $<2$, ED visit for trauma care, and unknown outcomes. Therefore, all enrolled patients had a qSOFA score $\geq 2$ and an increase in the SOFA score by $\geq 2$ points. Eligible patients were divided into the following three groups based on the presence of infection and sepsis severity: non-infectious organ failure, sepsis, and septic shock. All patients were carefully selected and reviewed by two ID experts and an emergency attending physician.

\section{Definitions}

According to Sepsis-3 definitions, sepsis is life-threatening organ dysfunction caused by a dysregulated host response to infection [1]. Septic shock is defined as a subset of sepsis in which profound circulatory, cellular, and metabolic abnormalities pose a greater risk of mortality than sepsis alone $[1,6]$. Sepsis-3 recommends the use of the qSOFA score to identify patients with poor prognosis outside the intensive care unit (ICU). The diagnostic criteria for sepsis include an increase in the SOFA score by $\geq 2$ points due to current infection. The criteria for septic shock include the requirement for a vasopressor to maintain a mean arterial pressure of $65 \mathrm{mmHg}$ and serum lactate level $>2 \mathrm{mmol} / \mathrm{L}$ despite adequate fluid resuscitation. Finally, the criteria for "non-infectious organ failure" include a positive qSOFA score and an increase in the SOFA score by $\geq 2$ points without current infection. Two independent ID experts reviewed all patients to determine the presence of current infection.

\section{Assays}

We sampled blood for presepsin and PCT from a peripheral vein within $6 \mathrm{~h}$ of ED presentation. Plasma presepsin levels were measured using an automated chemiluminescent enzyme immunoassay (PATHFAST system, LSI Medience Corporation, Tokyo, Japan). This novel system, based on the chemiluminescent enzyme immunoassay principle, has been developed to analyze blood samples that provide results within $17 \mathrm{~min}$ [18]. During incubation of the sample with alkaline phosphatase (ALP)labeled anti-presepsin polyclonal antibodies and anti-presepsin monoclonal antibody-coated magnetic particles, presepsin binds to anti-presepsin antibodies, assembling an immunocomplex with the ALPlabeled antibodies and mouse monoclonal antibody-coated magnetic particles. The manufacturerclaimed assay range of presepsin was $20-20,000 \mathrm{pg} / \mathrm{mL}$. Plasma presepsin concentrations were measured after the enrolled patients were discharged from the ED. Therefore, the assay results were unavailable to ED physicians and could not influence the management and disposition of the patients. 
PCT levels were measured using the Elecsys BRAHMS procalcitonin automated electrochemiluminescence assay (BRAHMS, Henningsdorf, Germany) on the Roche Cobas e-System (Roche Diagnostics, Basel, Switzerland). The manufacturer-claimed assay range of PCT was 0.02-100 $\mathrm{ng} / \mathrm{mL}$.

\section{Outcomes}

The primary outcome in the present study was 30-day mortality, and the secondary outcome was 90-day mortality. We excluded patients who were lost to follow-up from the 30-day and 90-day analyses.

\section{Statistical analysis}

Statistical analyses were performed using MedCalc for Windows (version 19.1.6; MedCalc Software, Mariakerke, Belgium) and SPSS (version 23.0; IBM, Armonk, NY, USA). Statistical significance was set at $\mathrm{p}<0.05$. To compare clinical characteristics and outcomes (7-, 14-, 30-, and 90-day mortalities) between the three groups, continuous variables, presented as median (interquartile range [IQR]), were compared using the Kruskal-Wallis test. Data were tested for normality using the Kolmogorov-Smirnov and Shapiro-Wilk tests. Categorical variables, presented as numbers and percentages, were compared using the chi-square test or Fisher's exact test. Pairwise comparisons were performed separately for each pair of three groups. The Bonferroni method was used to adjust the p-values in the post hoc analysis. To compare baseline characteristics between survivors and non-survivors among sepsis and septic shock patients, continuous variables, presented as the median (IQR), were compared using Student's t-test or the Mann-Whitney test according to the distribution. Categorical variables, presented as numbers and percentages, were compared using the chi-square test or Fisher's exact test. Receiver operating characteristic (ROC) curve analyses were performed for individual biomarkers, and their diagnostic value for sepsis and septic shock was compared. The discriminating capacities of the tested biomarkers are presented as areas under the curve (AUC) (95\% confidence interval [CI]). The optimal cut-off value was set for each ROC curve using the Youden index (maximum of the sum "sensitivity + specificity"). ROC curve analysis was performed for presepsin to predict 30-day mortality. The optimal cut-off value for predicting 30-day mortality was set for presepsin using the Youden index. Kaplan-Meier survival curve analysis and log-rank tests were performed according to the cut-off value of presepsin levels.

\section{Results}

\section{Study population and baseline characteristics}

During the study period, a total of 517 patients with positive qSOFA scores upon ED presentation were screened using i-SMS (Fig. 1). Among these, 97 patients were excluded due to refusal to participate $(n=$ $54)$, increase in SOFA score of $<2(n=31)$, admission for trauma care $(n=7)$, or unknown outcomes (loss to follow-up) ( $n=5)$. The final study population consisted of 420 patients. Of the patients, 142 had noninfectious organ failure, 141 had sepsis, and 137 had septic shock. A flowchart of the study population is shown in Fig. 1. Baseline characteristics of the study population are presented in Table 1. Patients with 
sepsis and septic shock were older than those with non-infectious organ failure. Sex and the Charlson comorbidity index did not differ between the three groups. Acute Physiology and Chronic Health Evaluation (APACHE) II, SOFA, National Early Warning (NEWS), and Modified Early Warning (MEWS) scores were significantly higher in sepsis and septic shock patients than in non-infectious organ failure patients. The 7-, 14-, 30-, and 90-day mortality rates were higher in septic shock patients than in the other groups. Table 2 shows the principal clinical diagnoses of non-infectious organ failure patients according to the affected organ systems: 52 , central nervous; 41 , cardiovascular; 21 , respiratory; 19 , hepatobiliary; 14 , renal; and 7, coagulation. The most common diagnoses were hypovolemic shock, metabolic encephalopathy, cerebral hemorrhage, heart failure, chronic obstructive pulmonary disease, asthma, seizure, and liver cirrhosis (Table 2). 
Table 1

Baseline characteristics of the study population

\begin{tabular}{|c|c|c|c|c|}
\hline Variables & $\begin{array}{l}\text { Non-infectious organ } \\
\text { failure } \\
(n=142)\end{array}$ & $\begin{array}{l}\text { Sepsis } \\
(n=141)\end{array}$ & $\begin{array}{l}\text { Septic shock } \\
(n=137)\end{array}$ & $\begin{array}{l}p \\
\text { value }\end{array}$ \\
\hline Age, median (IQR) & $66(51-80)$ & $76(67-83)$ & $77(62-83)$ & $<.001$ \\
\hline Male, n (\%) & $85(56)$ & $85(62)$ & $74(57)$ & 0.519 \\
\hline Charlson comorbidity index & $4(3-5)$ & $3(3-5)$ & $5(4-6)$ & 0.182 \\
\hline \multicolumn{5}{|l|}{ Site of infection, $\mathrm{n}(\%)$} \\
\hline Respiratory & & $84(60)$ & $81(59)$ & 0.713 \\
\hline Genitourinary & & $35(25)$ & $33(24)$ & 0.367 \\
\hline Gastrointestinal & & $14(10)$ & $13(10)$ & 0.386 \\
\hline Others & & $13(9)$ & $15(11)$ & 0.281 \\
\hline $\begin{array}{l}\text { APACHE II score, median } \\
\text { (IQR) }\end{array}$ & $23(18-29)$ & $26(22-32)$ & $29(25-33)$ & $<.001$ \\
\hline SOFA score, median (IQR) & $6(3-8)$ & $6(5-8)$ & $10(8-12)$ & $<.001$ \\
\hline NEWS, median (IQR) & $9(7-11)$ & $10(8-12)$ & $11(9-14)$ & $<.001$ \\
\hline MEWS, median (IQR) & $5(4-7)$ & $6(5-7)$ & $6(5-8)$ & $<.001$ \\
\hline \multirow{2}{*}{$\underset{(\mathrm{IQR})}{\mathrm{WBC}}\left(\times 10^{9} / \mathrm{L}\right)$, median } & 11.30 & 11.94 & 11.22 & \multirow[t]{2}{*}{0.343} \\
\hline & $(8.17-14.63)$ & $(8.24-17.06)$ & $(6.68-20.04)$ & \\
\hline CRP (mg/dL), median (IQR) & $0.53(0.13-2.42)$ & $\begin{array}{l}7.50(3.33- \\
16.66)\end{array}$ & $\begin{array}{l}10.07(3.99- \\
20.70)\end{array}$ & $<.001$ \\
\hline $\begin{array}{l}\text { Procalcitonin }(\mathrm{ng} / \mathrm{mL}) \text {, } \\
\text { median (IQR) }\end{array}$ & $0.10(0.05-0.25)$ & $\begin{array}{l}0.98(0.35- \\
4.25)\end{array}$ & $\begin{array}{l}4.22(0.88- \\
21.02)\end{array}$ & $<.001$ \\
\hline $\begin{array}{l}\text { Presepsin }(\mathrm{pg} / \mathrm{mL}) \text {, median } \\
(\mathrm{IQR})\end{array}$ & $286(170-417)$ & $\begin{array}{l}792(450- \\
1273)\end{array}$ & $\begin{array}{l}1287(589- \\
2366)\end{array}$ & $<.001$ \\
\hline $\begin{array}{l}\text { Lactate }(\mathrm{mmol} / \mathrm{L}) \text {, median } \\
\text { (IQR) }\end{array}$ & $2.5(1.5-5.1)$ & $2.2(1.5-4.9)$ & $4.4(2.4-8.1)$ & $\begin{array}{l}< \\
0.001\end{array}$ \\
\hline
\end{tabular}

IQR, interquartile range; APACHE, Acute Physiology and Chronic Health Evaluation; SOFA, sepsisrelated organ failure assessment; NEWS, National Early Warning Score; MEWS, Modified Early Warning Score; WBC, White Blood Cell; CRP, C-reactive protein 


\begin{tabular}{|c|c|c|c|c|}
\hline Variables & $\begin{array}{l}\text { Non-infectious organ } \\
\text { failure } \\
(n=142)\end{array}$ & $\begin{array}{l}\text { Sepsis } \\
(n=141)\end{array}$ & $\begin{array}{l}\text { Septic shock } \\
(n=137)\end{array}$ & $\begin{array}{l}p \\
\text { value }\end{array}$ \\
\hline 7-day mortality & $11(7.2)$ & $11(8.0)$ & 33 (25.2) & $\hat{0}_{0.001}$ \\
\hline 14-day mortality & $16(10.5)$ & 19 (13.9) & $40(30.5)$ & $\begin{array}{l}< \\
0.001\end{array}$ \\
\hline 30-day mortality & $20(13.2)$ & $22(16.1)$ & 47 (35.9) & $\begin{array}{l}< \\
0.001\end{array}$ \\
\hline 90-day mortality & $21(13.8)$ & $33(24.1)$ & 52 (39.7) & $\begin{array}{l}<.001 \\
0.001\end{array}$ \\
\hline \multicolumn{5}{|c|}{$\begin{array}{l}\text { IQR, interquartile range; APACHE, Acute Physiology and Chronic Health Evaluation; SOFA, sepsis- } \\
\text { related organ failure assessment; NEWS, National Early Warning Score; MEWS, Modified Early } \\
\text { Warning Score; WBC, White Blood Cell; CRP, C-reactive protein }\end{array}$} \\
\hline
\end{tabular}


Table 2

Principal diagnoses of non-infectious organ failure patients $(n=142)$ according to the affected organ systems.

\begin{tabular}{|c|c|c|}
\hline Organs & Main clinical diagnoses & $\mathrm{n}(\%)$ \\
\hline Central nervous & Cerebral hemorrhage (ICH, IVH, SAH and SDH) & $12(8.5)$ \\
\hline \multirow[t]{6}{*}{$(n=52)$} & Cerebral infarction & $5(3.5)$ \\
\hline & Seizure & $11(7.7)$ \\
\hline & Hypoglycemia & $4(2.8)$ \\
\hline & Metabolic encephalopathy & $13(9.2)$ \\
\hline & Heat stroke & $2(1.4)$ \\
\hline & Others & $5(3.5)$ \\
\hline \multirow{5}{*}{$\begin{array}{l}\text { Cardiovascular } \\
(\mathrm{n}=41)\end{array}$} & Heart failure & $12(8.5)$ \\
\hline & Pulmonary embolism & $5(3.5)$ \\
\hline & Hypovolemic (hemorrhagic) shock & $17(12.0)$ \\
\hline & Aortic dissection & $4(2.8)$ \\
\hline & Others & $3(2.1)$ \\
\hline \multirow{4}{*}{$\begin{array}{l}\text { Respiratory } \\
(n=21)\end{array}$} & COPD or asthma & $12(8.5)$ \\
\hline & Malignancy in respiratory system & $4(2.8)$ \\
\hline & Airway obstruction & $3(2.1)$ \\
\hline & Others & $2(1.4)$ \\
\hline \multirow{3}{*}{$\begin{array}{l}\text { Hepatobiliary } \\
(\mathrm{n}=19)\end{array}$} & Liver cirrhosis aggravation & $11(7.7)$ \\
\hline & Hepatobiliary malignancy & $5(3.5)$ \\
\hline & Others & $3(2.1)$ \\
\hline \multirow{2}{*}{$\begin{array}{l}\text { Renal } \\
(\mathrm{n}=14)\end{array}$} & Acute kidney injury & $9(6.3)$ \\
\hline & Underdialysis in pre-existing CKD & $5(3.5)$ \\
\hline \multirow{2}{*}{$\begin{array}{l}\text { Coagulation } \\
(n=7)\end{array}$} & Hematologic malignancy & $4(2.8)$ \\
\hline & Thrombocytopenia & $3(2.1)$ \\
\hline
\end{tabular}


A comparison of presepsin, PCT, and CRP levels among all patients with organ failure is shown in Fig. 2 and Table 1. Presepsin, PCT, and CRP levels were significantly higher in sepsis and septic shock patients than in non-infectious organ failure patients. Presepsin and PCT levels were significantly higher in septic shock patients than in sepsis patients. In contrast, we observed no significant differences in CRP levels between the sepsis and septic shock groups (Fig. 2).

\section{Diagnostic value of presepsin, PCT, and CRP}

ROC curve analyses to discriminate between the three groups are shown in Fig. 3 and Table 3 . The optimal cut-off value for presepsin to discriminate between sepsis and non-infectious organ failure was $582 \mathrm{pg} / \mathrm{mL}$ (sensitivity, 70.1; specificity, 89.4; AUC, 0.877; 95\% Cl, 0.841-0.906; $p<0.001$ ). The cut-off value for presepsin to discriminate between sepsis and septic shock was $1285 \mathrm{pg} / \mathrm{mL}$ (sensitivity, 50.4; specificity, 76.6; AUC, $0.618 ; 95 \% \mathrm{Cl}, 0.558-0.675 ; \mathrm{p}<0.001)$. The optimal cut-off value for PCT to discriminate between sepsis and non-infectious organ failure was $0.51 \mathrm{ng} / \mathrm{mL}$ (sensitivity, 75.5; specificity, 93.0; AUC, $0.908 ; 95 \% \mathrm{Cl}, 0.877-0.934 ; \mathrm{p}<0.001)$. The cut-off value for PCT to discriminate between sepsis and septic shock was $2.81 \mathrm{ng} / \mathrm{mL}$ (sensitivity, 59.1; specificity, 70.9; AUC, 0.678; 95\% Cl, $0.619-0.732 ; p<0.001)$. The optimal cut-off value for CRP to discriminate between sepsis and noninfectious organ failure was $3.53 \mathrm{mg} / \mathrm{L}$ (sensitivity, 77.0; specificity, 85.2; AUC, 0.858; 95\% Cl, 0.821$0.890 ; p<0.001$ ). The cut-off value for CRP to discriminate between sepsis and septic shock was 6.62 $\mathrm{mg} / \mathrm{L}$ (sensitivity, 65.7; specificity, 46.8; AUC, 0.559; 95\% Cl, 0.498-0.618; $\mathrm{p}=0.088$ ). 
Table 3

Comparisons of the discriminating capacities between tested biomarkers presented as areas under the curve $(95 \% \mathrm{Cl})$

\begin{tabular}{|c|c|c|c|c|c|}
\hline Tested biomarker & $\operatorname{AUC}(95 \% \mathrm{Cl})$ & $\begin{array}{l}p \\
\text { value }\end{array}$ & $\begin{array}{l}\text { Cut-off } \\
\text { value }\end{array}$ & $\begin{array}{l}\text { Sensitivity, } \\
\text { (\%) }\end{array}$ & $\begin{array}{l}\text { Specificity, } \\
\text { (\%) }\end{array}$ \\
\hline \multicolumn{6}{|l|}{ Presepsin } \\
\hline $\begin{array}{l}\text { Sepsis vs. Non-infectious } \\
\text { organ failure }\end{array}$ & $\begin{array}{l}0.877(0.841- \\
0.906)\end{array}$ & $\dot{0} 001$ & $\begin{array}{l}582 \\
(\mathrm{pg} / \mathrm{mL})\end{array}$ & 70.1 & 89.4 \\
\hline Septic shock vs. Sepsis & $\begin{array}{l}0.618(0.558- \\
0.675)\end{array}$ & $<001$ & $\begin{array}{l}1285 \\
(\mathrm{pg} / \mathrm{mL})\end{array}$ & 50.4 & 76.6 \\
\hline \multicolumn{6}{|l|}{ Procalcitonin } \\
\hline $\begin{array}{l}\text { Sepsis vs. Non-infectious } \\
\text { organ failure }\end{array}$ & $\begin{array}{l}0.908(0.877- \\
0.934)\end{array}$ & $<.001$ & $\begin{array}{l}0.51 \\
(\mathrm{ng} / \mathrm{mL})\end{array}$ & 75.5 & 93.0 \\
\hline Septic shock vs. Sepsis & $\begin{array}{l}0.678(0.619- \\
0.732)\end{array}$ & $<0.001$ & $\begin{array}{l}2.81 \\
(\mathrm{ng} / \mathrm{mL})\end{array}$ & 59.1 & 70.9 \\
\hline \multicolumn{6}{|l|}{ CRP } \\
\hline $\begin{array}{l}\text { Sepsis vs. Non-infectious } \\
\text { organ failure }\end{array}$ & $\begin{array}{l}0.858(0.821- \\
0.890)\end{array}$ & $<.001$ & $\begin{array}{l}3.53 \\
(\mathrm{mg} / \mathrm{L})\end{array}$ & 77.0 & 85.2 \\
\hline Septic shock vs. Sepsis & $\begin{array}{l}0.559(0.498- \\
0.618)\end{array}$ & 0.088 & $\begin{array}{l}6.62 \\
(\mathrm{mg} / \mathrm{L})\end{array}$ & 65.7 & 46.8 \\
\hline
\end{tabular}

\section{Prognostic value of presepsin}

The 30 -day mortality rate was $27 \%$ (74/278) of the sepsis and septic shock patients (Table 4). We compared the clinical variables between 30-day survivor and non-survivor sepsis patients (non-infectious organ failure excluded). Survivors and non-survivors did not differ in age, sex, Charlson comorbidity index, sites of infection, or CRP and PCT levels. APACHE II, SOFA score, NEWS, and MEWS were significantly higher in non-survivors. Presepsin levels were significantly higher in non-survivors than in survivors $(1142$ [650-2039] ng/mL vs. 815 [460-1678] ng/mL; $p<0.001)$. Lactate levels were significantly higher in non-survivors than in survivors $(6.0[2.9-9.9] \mathrm{mmol} / \mathrm{L}$ vs. $2.6[1.6-5.2] \mathrm{mmol} / \mathrm{L} ; \mathrm{p}<$ 0.001). 
Table 4

Comparison of clinical variables between 30-day survivor and non-survivor sepsis patients (noninfectious organ failure patients excluded).

\begin{tabular}{|c|c|c|c|c|}
\hline Variables & $\begin{array}{l}\text { All septic } \\
\text { patients } \\
(n=278)\end{array}$ & $\begin{array}{l}\text { Survivors } \\
(n=204)\end{array}$ & $\begin{array}{l}\text { Non-survivors } \\
(n=74)\end{array}$ & $\begin{array}{l}p \\
\text { value }\end{array}$ \\
\hline Age, median (IQR) & $77(64-84)$ & $77(64-83)$ & $78(65-85)$ & 0.210 \\
\hline Male, $\mathrm{n}(\%)$ & $162(58)$ & $120(59)$ & $42(57)$ & 0.757 \\
\hline Charlson comorbidity index & $4(3-5)$ & $3(3-5)$ & $5(4-6)$ & 0.157 \\
\hline \multicolumn{5}{|l|}{ Site of infection, $\mathrm{n}(\%)$} \\
\hline Respiratory & $165(59)$ & $119(58)$ & $46(62)$ & 0.658 \\
\hline Genitourinary & $68(24)$ & $48(24)$ & $20(27)$ & 0.412 \\
\hline Gastrointestinal & $27(10)$ & $20(10)$ & $7(9)$ & 0.348 \\
\hline Others & $28(10)$ & $21(10)$ & $7(9)$ & 0.316 \\
\hline APACHE II score, median (IQR) & $28(24-33)$ & $27(22-31)$ & $31(26-37)$ & $<.001$ \\
\hline SOFA score, median (IQR) & $9(6-11)$ & $8(6-10)$ & $11(9-12)$ & $<0.001$ \\
\hline NEWS, median (IQR) & $11(9-13)$ & $10(9-12)$ & $12(10-14)$ & 0.002 \\
\hline MEWS, median (IQR) & $6(5-7)$ & $6(5-7)$ & $6(5-9)$ & 0.043 \\
\hline \multirow[t]{2}{*}{ WBC $\left(\times 10^{9} / \mathrm{L}\right)$, median (IQR) } & 11.68 & 11.91 & 10.76 & 0.009 \\
\hline & $(7.65-18.07)$ & $(8.38-19.66)$ & $(5.06-15.75)$ & \\
\hline CRP (mg/L), median (IQR) & $\begin{array}{l}9.09(3.87- \\
17.34)\end{array}$ & $\begin{array}{l}8.69(3.57- \\
17.07)\end{array}$ & $\begin{array}{l}10.75(4.80- \\
19.04)\end{array}$ & 0.270 \\
\hline $\begin{array}{l}\text { Procalcitonin }(\mathrm{ng} / \mathrm{mL}) \text {, median } \\
\text { (IQR) }\end{array}$ & $\begin{array}{l}1.74(0.51- \\
8.51)\end{array}$ & $\begin{array}{l}1.61(0.47- \\
8.95)\end{array}$ & $2.06(0.62-7.22)$ & 0.666 \\
\hline $\begin{array}{l}\text { Presepsin }(\mathrm{pg} / \mathrm{mL}) \text {, median } \\
\text { (IQR) }\end{array}$ & $934(512-1802)$ & $\begin{array}{l}815(460- \\
1678)\end{array}$ & $\begin{array}{l}1142(650- \\
2039)\end{array}$ & $<.001$ \\
\hline Lactate (mmol/L), median (IQR) & $\begin{array}{l}3.1(1.9-6.6) 16 \\
+2\end{array}$ & $2.6(1.6-5.2)$ & $6.0(2.9-9.9)$ & $\begin{array}{l}< \\
0.001\end{array}$ \\
\hline
\end{tabular}

The optimal cut-off value for presepsin for predicting 30-day mortality was $821 \mathrm{pg} / \mathrm{mL}$ (sensitivity 68.9 , specificity 50.5 ; AUC $0.605 ; 95 \% \mathrm{Cl} 0.545-0.663 ; \mathrm{p}=0.005$ ) in patients with sepsis and septic shock. The 
30-day mortality rates were $18.4 \%(23 / 125)$ in patients with lower presepsin levels $(<821 \mathrm{pg} / \mathrm{mL})$ and $33.3 \%$ (51/153) in patients with higher presepsin levels ( $\geq 821 \mathrm{pg} / \mathrm{mL}$ ). Kaplan-Meier survival curve analysis showed that patients with higher presepsin levels had significantly higher mortality than patients with lower presepsin levels (log-rank test; $p=0.004$ ) (Fig. 4).

\section{Discussion}

To our knowledge, this is the largest prospective observational study on both the diagnostic and prognostic value of presepsin in non-infectious organ failure, sepsis, and septic shock, in accordance with the latest Sepsis-3 definitions. Presepsin had excellent accuracy in discriminating sepsis from noninfectious organ failure and had fair accuracy in discriminating septic shock from sepsis. The discriminating power of presepsin was comparable to that of PCT in patients with non-infectious organ failure, sepsis, and septic shock. The prognostic value of presepsin was superior to that of PCT and CRP in patients with sepsis and septic shock.

Our results showed that the optimal cut-off value to discriminate sepsis (including shock) from noninfectious organ failure was 582 pg/mL (AUC 0.877; sensitivity 70.1; specificity 89.4). Several studies have reported different performance efficiencies of presepsin as an indicator in different types of infections. Optimal cut-off values (sensitivity, specificity) to discriminate sepsis from non-sepsis were 907 $(70 \%, 83 \%)$ [19], 686 (47\%, 91\%) [20], 670 (70\%, 81\%) [21], 729 (81\%, 63\%) [22], 600 (86\%, 72\%) [23], 600 $(79 \%, 62 \%)$ [24], 542 (77\%, 76\%) [25], 430 (88\%, 82\%) [26], and 466 (90\%, 55\%) pg/mL [27], respectively. Different cut-off values reported by these studies may be caused by heterogeneity of the studies in the clinical setting (ED vs. ICU), study design (prospective vs. retrospective), sepsis severity, comorbidities, or type of sample (plasma vs. whole blood vs. serum). However, these studies were performed according to the previous Sepsis-2 definitions.

A recent study using Sepsis-3 reported that presepsin and PCT were superior to CRP and lactate in discriminating sepsis, including shock from non-sepsis with SIRS and SOFA score $\geq 2$ [17]. The AUC values used to discriminate sepsis from non-sepsis were 0.88 for presepsin, 0.81 for PCT, 0.65 and CRP. The AUC value of presepsin in the study was similar to that in our study (AUC: 0.877), and the sensitivity, specificity, positive predictive value, negative predictive value, and accuracy of presepsin for diagnosing sepsis (including shock) using a cutoff value of $508 \mathrm{pg} / \mathrm{mL}$ were $87 \%, 86 \%, 93 \%, 76 \%$, and $87 \%$, respectively. The cutoff value found in the study $(508 \mathrm{pg} / \mathrm{mL})$ was relatively lower than that in our study $(582 \mathrm{pg} / \mathrm{mL})$. Our study is similar to the previous study in that it was performed in the ED according to the latest Sepsis-3 definitions. However, we included a much larger population and used qSOFA as a screening tool instead of SIRS because SIRS is no longer recommended as a diagnostic criterion for sepsis in the new definitions [1]. These differences might have caused the differences in cutoff values between the two studies. Another study using Sepsis-3 in a Spanish population also reported that presepsin can effectively discriminate sepsis from non-infectious SIRS [16]. However, these two studies using Sepsis-3 did not evaluate the prognostic capacity of presepsin. 
A previous study reported that presepsin was superior to PCT and CRP in discriminating sepsis from SIRS in acute abdominal conditions [28]. In contrast, another study showed that the diagnostic capacity of presepsin was not superior to that of PCT [20], suggesting that its introduction and routine use in clinical practice were not justified. Another study also reported that presepsin did not outperform traditional biomarkers in diagnosing sepsis from SIRS and in the prognosis of mortality [29]. In fact, results reported about the diagnostic value of presepsin are controversial, probably due to different study designs or settings. Therefore, specific decision levels are required to determine the clinical roles of presepsin in different settings of non-infectious and infectious diseases [30].

A multicenter prospective study reported that mean presepsin levels were significantly higher in nonsurvivors of sepsis than in survivors [24]. However, in that study, no significant correlation was observed between PCT levels and survival outcomes [24]. Similar to the previous study, our results showed that presepsin levels were significantly higher in non-survivors than in survivors. No significant difference in PCT levels was observed between non-survivors and survivors. In our study, Kaplan-Meier survival curve analysis according to the optimal cut-off value of presepsin showed that 30-day mortality was significantly higher in patients with higher presepsin levels. In accordance with our study, a systemic review and meta-analysis revealed that presepsin levels on the first day had prognostic value in predicting in-hospital or 30-day mortality in adult patients with sepsis [31]. The combination of presepsin with PCT, Galectin-3, and soluble suppression of tumorigenicity-2 showed better performance in predicting mortality than the single use of presepsin in sepsis patients [10]. The study demonstrated that the combination of presepsin with other biomarkers could help clinicians predict mortality. Further studies with larger cohorts are required to determine the optimal cut-off value of presepsin for predicting mortality associated with sepsis.

There are some limitations to the present study. First, although the present study included a large sample size compared to previous studies, it was a single-center ED-based study. Thus, our results may not be applicable to other EDs or ICUs. Second, only plasma presepsin levels in the ED were measured, and follow-up changes of the marker were not determined. Although a previous study reported that dynamic monitoring of presepsin could effectively predict prognosis [32,33], other trials demonstrated that single measurements of presepsin in the ED also had valuable prognostic capacity in sepsis patients [12, 24]. Third, although a previous study reported that presepsin levels were markedly elevated in chronic kidney disease patients receiving hemodialysis [34], our study did not consider kidney function. Further studies are needed to investigate the impact of kidney dysfunction on presepsin levels using repetitive marker measurements. Fourth, because the present study included patients with organ dysfunction enrolled in the ED, this might have resulted in selection bias. Nevertheless, we postulate that our study, based on an organ failure cohort, could reflect the clinical characteristics of the patients in a real ED setting.

\section{Conclusions}

The present study, according to the Sepsis-3 definitions, demonstrated the diagnostic and prognostic value of presepsin levels among patients with non-infectious organ failure, sepsis, and septic shock. Its 
ability to discriminate sepsis, including shock, from non-infectious organ failure was excellent, and its prognostic ability could help clinicians to prognosticate patients with sepsis and septic shock. Further multicenter prospective studies with larger populations are needed to determine the optimal cut-off value of presepsin for the diagnosis and prognosis of sepsis.

\section{Abbreviations}

APACHE: Acute Physiology and Chronic Health Evaluation; AUC: Area under the curve; Cl: Confidence interval; CRP: C-reactive protein; ED: Emergency department; ID: Infectious diseases; ICU: Intensive care unit; IQR: Interquartile range; MEWS: Modified Early Warning Score; NEWS: National Early Warning Score; PCT: Procalcitonin; qSOFA: Quick sepsis-related organ failure assessment; ROC: Receiver operating characteristic; SIRS: Systemic inflammatory response syndrome; SOFA: Sepsis-related organ failure assessment; SSC: Surviving Sepsis Campaign.

\section{Declarations}

\section{Acknowledgements}

We thank researchers Tae-ho Lee and Hye-yoon Jung for their contributions to the project. We also thank Editage for thorough English revision.

\section{Authors' contributions}

JS, DWP, HS, and SL contributed to the conception and design of the study. JS, HC, SA, JK, JP and JC contributed to data acquisition, analysis, and interpretation of data. The first draft of the manuscript was written by JS and SL. The manuscript was reviewed and edited by JS and DWP. JS and JC performed the statistical analyses. All authors read and approved the submission of the final manuscript.

\section{Funding}

This research was funded by the National Research of Korea (NRF) grant funded by the Korean government (MSIT) (grant number 2020R1C1C1010362) and by grants from Korea University Ansan Hospital (grant number 01903721).

\section{Availability of data and materials}

The data supporting this study are available from the corresponding author on reasonable request.

\section{Ethics approval and consent to participate}

The present study was approved by the Institutional Review Board of Korea University Ansan Hospital. Written informed consent was obtained from all patients or their legal representatives. 
Not applicable

\section{Competing interests}

On behalf of all authors, the corresponding author states that there are no competing interests.

\section{Author details}

${ }^{1}$ Department of Emergency Medicine, Korea University Ansan Hospital, Ansan, Republic of Korea. ${ }^{2}$ Division of Infectious Diseases, Department of Internal Medicine, Korea University Ansan Hospital, Ansan, Republic of Korea. ${ }^{3}$ Medical Science Research Center, Korea University Ansan Hospital, Ansan, Republic of Korea.

\section{References}

1. Singer M, Deutschman CS, Seymour CW, Shankar-Hari M, Annane D, Bauer M, et al. The Third International Consensus Definitions for Sepsis and Septic Shock (Sepsis-3). JAMA. 2016;315:80110.

2. Angus DC, van der Poll T. Severe sepsis and septic shock. N Engl J Med. 2013;369:840-51.

3. Gaieski DF, Edwards JM, Kallan MJ, Carr BG. Benchmarking the incidence and mortality of severe sepsis in the United States. Crit Care Med. 2013;41:1167-74.

4. Rhodes A, Evans LE, Alhazzani W, Levy MM, Antonelli M, Ferrer R, et al. Surviving Sepsis Campaign: International Guidelines for Management of Sepsis and Septic Shock: 2016. Crit Care Med. 2017;45:486-552.

5. Song J, Cho H, Park DW, Ahn S, Kim JY, Seok H, et al. The Effect of the Intelligent Sepsis Management System on Outcomes among Patients with Sepsis and Septic Shock Diagnosed According to the Sepsis-3 Definition in the Emergency Department. J Clin Med. 2019;8:1800.

6. Shankar-Hari M, Phillips GS, Levy ML, Seymour CW, Liu VX, Deutschman CS, et al. Developing a New Definition and Assessing New Clinical Criteria for Septic Shock: For the Third International Consensus Definitions for Sepsis and Septic Shock (Sepsis-3). JAMA. 2016;315:775-87.

7. Kibe S, Adams K, Barlow G. Diagnostic and prognostic biomarkers of sepsis in critical care. J Antimicrob Chemother. 2011;66(Suppl 2):ii33-40.

8. Larsen FF, Petersen JA. Novel biomarkers for sepsis: A narrative review. Eur J Intern Med. 2017;45:46-50.

9. Wacker C, Prkno A, Brunkhorst FM, Schlattmann P. Procalcitonin as a diagnostic marker for sepsis: a systematic review and meta-analysis. Lancet Infect Dis. 2013;13:426-35.

10. Kim H, Hur M, Moon HW, Yun YM, Di Somma S. Multi-marker approach using procalcitonin, presepsin, galectin-3, and soluble suppression of tumorigenicity 2 for the prediction of mortality in sepsis. Ann Intensive Care. 2017;7:27. 
11. Masson S, Caironi P, Fanizza C, Thomae R, Bernasconi R, Noto A, et al. Circulating presepsin (soluble CD14 subtype) as a marker of host response in patients with severe sepsis or septic shock: data from the multicenter, randomized ALBIOS trial. Intensive Care Med. 2015;41:12-20.

12. Liu B, Chen YX, Yin Q, Zhao YZ, Li CS. Diagnostic value and prognostic evaluation of Presepsin for sepsis in an emergency department. Crit Care. 2013;17:R244.

13. Masson S, Caironi P, Spanuth E, Thomae R, Panigada M, Sangiorgi G, et al. Presepsin (soluble CD14 subtype) and procalcitonin levels for mortality prediction in sepsis: data from the Albumin Italian Outcome Sepsis trial. Crit Care. 2014;18:R6.

14. Kondo Y, Umemura Y, Hayashida K, Hara Y, Aihara M, Yamakawa K. Diagnostic value of procalcitonin and presepsin for sepsis in critically ill adult patients: a systematic review and meta-analysis. $\mathrm{J}$ Intensive Care. 2019;7:22.

15. Wu CC, Lan HM, Han ST, Chaou CH, Yeh CF, Liu SH, et al. Comparison of diagnostic accuracy in sepsis between presepsin, procalcitonin, and C-reactive protein: a systematic review and metaanalysis. Ann Intensive Care. 2017;7:91.

16. Contenti J, Occelli C, Lemoel F, Ferrari P, Levraut J. Presepsin versus other biomarkers to predict sepsis and septic shock in patients with infection defined by Sepsis-3 criteria: the PREDI study of diagnostic accuracy. Emergencias. 2019;31:311-7.

17. Yamamoto T, Nishimura T, Kaga S, Uchida K, Tachibana Y, Esaki M, et al. Diagnostic accuracy of presepsin for sepsis by the new Sepsis-3 definitions. Am J Emerg Med. 2019;37:1936-41.

18. Memar MY, Baghi HB. Presepsin. A promising biomarker for the detection of bacterial infections. Biomed Pharmacother. 2019;111:649-56.

19. Ali FT, Ali MA, Elnakeeb MM, Bendary HN. Presepsin is an early monitoring biomarker for predicting clinical outcome in patients with sepsis. Clin Chim Acta. 2016;460:93-101.

20. de Guadiana Romualdo LG, Torrella PE, Acebes SR, Otón MDA, Sánchez RJ, Holgado AH, et al. Diagnostic accuracy of presepsin (SCD14-ST) as a biomarker of infection and sepsis in the emergency department. Clin Chim Acta. 2017;464:6-11.

21. Nakamura $Y$, Ishikura $H$, Nishida T, Kawano $Y$, Yuge R, Ichiki R, et al. Usefulness of presepsin in the diagnosis of sepsis in patients with or without acute kidney injury. BMC Anesthesiol. 2014;14:88.

22. de Guadiana Romualdo LG, Torrella PE, González MV, Sánchez RJ, Holgado AH, Freire AO, et al. Diagnostic accuracy of presepsin (soluble CD14 subtype) for prediction of bacteremia in patients with systemic inflammatory response syndrome in the Emergency Department. Clin Biochem. 2014;47:505-8.

23. Sargentini V, Ceccarelli G, D'Alessandro M, Collepardo D, Morelli A, D'Egidio A, et al. Presepsin as a potential marker for bacterial infection relapse in critical care patients. A preliminary study. Clin Chem Lab Med. 2015;53:567-73.

24. Ulla M, Pizzolato E, Lucchiari M, Loiacono M, Soardo F, Forno D, et al. Diagnostic and prognostic value of presepsin in the management of sepsis in the emergency department: a multicenter prospective study. Crit Care. 2013;17:R168.

Page $17 / 21$ 
25. Cakır Madenci Ö, Yakupoğlu S, Benzonana N, Yücel N, Akbaba D. Orçun Kaptanağası A. Evaluation of soluble CD14 subtype (presepsin) in burn sepsis. Burns. 2014;40:664-9.

26. Kweon OJ, Choi JH, Park SK, Park AJ. Usefulness of presepsin (SCD14 subtype) measurements as a new marker for the diagnosis and prediction of disease severity of sepsis in the Korean population. $J$ Crit Care. 2014;29:965-70.

27. Klouche K, Cristol JP, Devin J, Gilles V, Kuster N, Larcher R, et al. Diagnostic and prognostic value of soluble CD14 subtype (Presepsin) for sepsis and community-acquired pneumonia in ICU patients. Ann Intensive Care. 2016;6:59.

28. Vodnik T, Kaljevic G, Tadic T, Majkic-Singh N. Presepsin (sCD14-ST) in preoperative diagnosis of abdominal sepsis. Clin Chem Lab Med. 2013;51:2053-62.

29. Brodska H, Valenta J, Pelinkova K, Stach Z, Sachl R, Balik M, et al. Diagnostic and prognostic value of presepsin vs. established biomarkers in critically ill patients with sepsis or systemic inflammatory response syndrome. Clin Chem Lab Med. 2018;56:658-68.

30. Giavarina D, Carta M. Determination of reference interval for presepsin, an early marker for sepsis. Biochem Med (Zagreb). 2015;25:64-8.

31. Yang HS, Hur M, Yi A, Kim H, Lee S, Kim SN. Prognostic value of presepsin in adult patients with sepsis: Systematic review and meta-analysis. PLoS One. 2018;13:e0191486.

32. Behnes M, Bertsch T, Lepiorz D, Lang S, Trinkmann F, Brueckmann M, et al. Diagnostic and prognostic utility of soluble CD 14 subtype (presepsin) for severe sepsis and septic shock during the first week of intensive care treatment. Crit Care. 2014;18:507.

33. Yu H, Qi Z, Hang C, Fang Y, Shao R, Li C. Evaluating the value of dynamic procalcitonin and presepsin measurements for patients with severe sepsis. Am J Emerg Med. 2017;35:835-41.

34. Nagata T, Yasuda Y, Ando M, Abe T, Katsuno T, Kato S, et al. Clinical impact of kidney function on presepsin levels. PLoS One. 2015;10:e0129159.

\section{Figures}




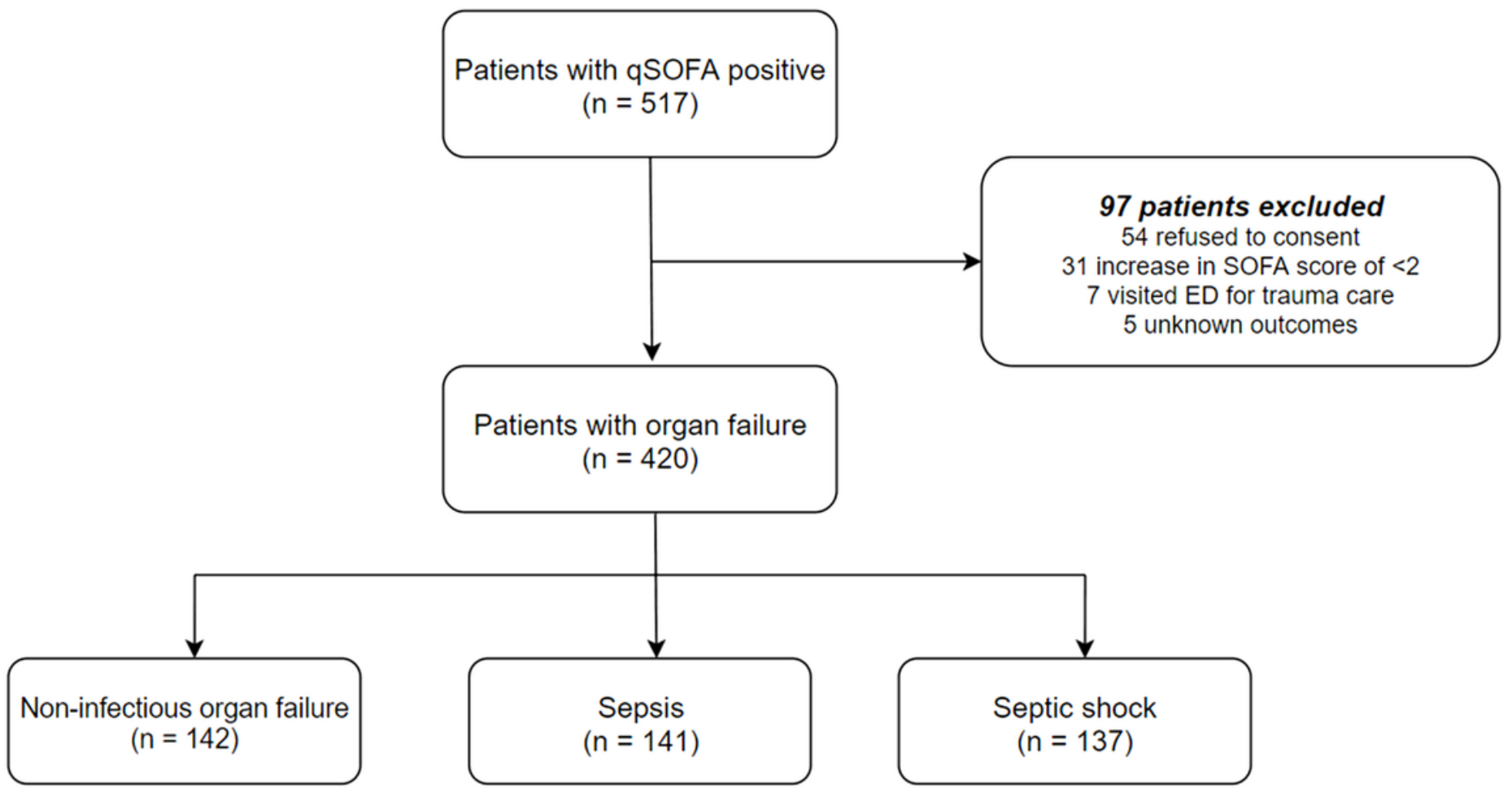

\section{Figure 1}

Flowchart of the study population.
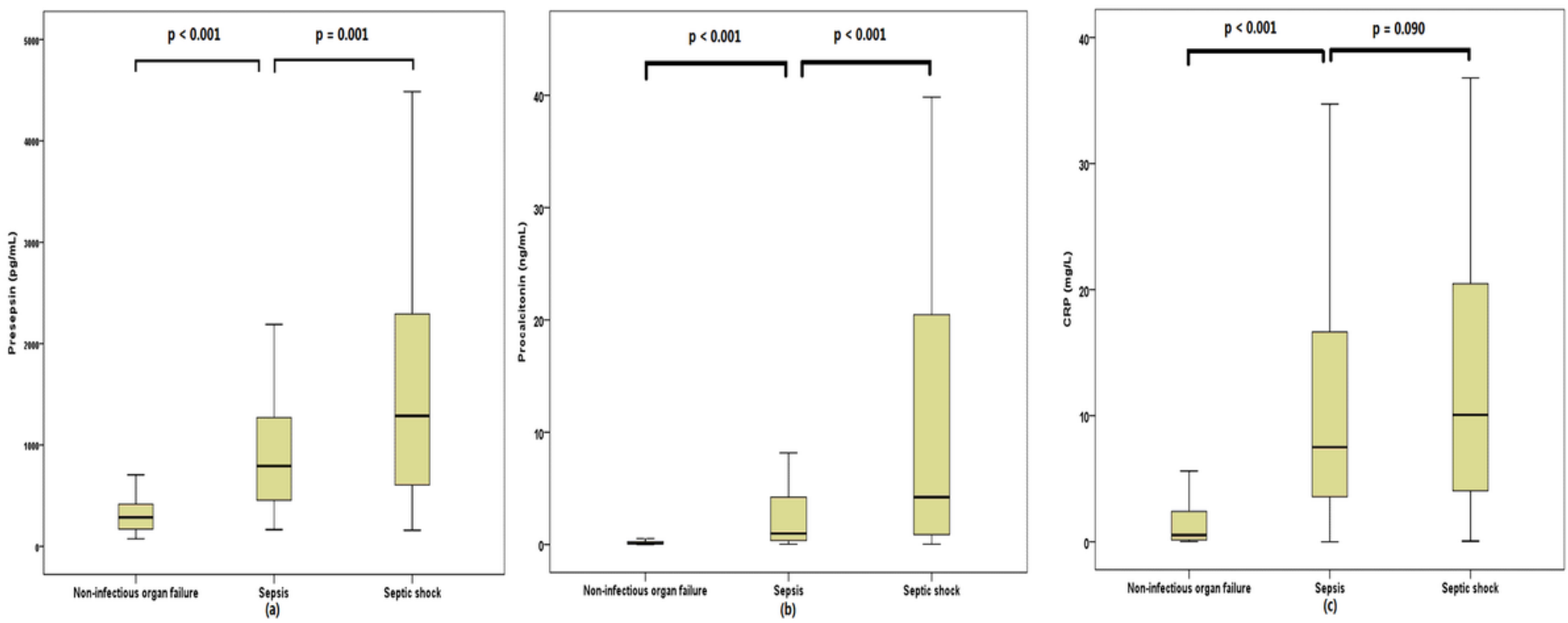

Figure 2 
Comparison of presepsin (a), procalcitonin (b), and CRP (c) levels in emergency department among all patients with organ failure.
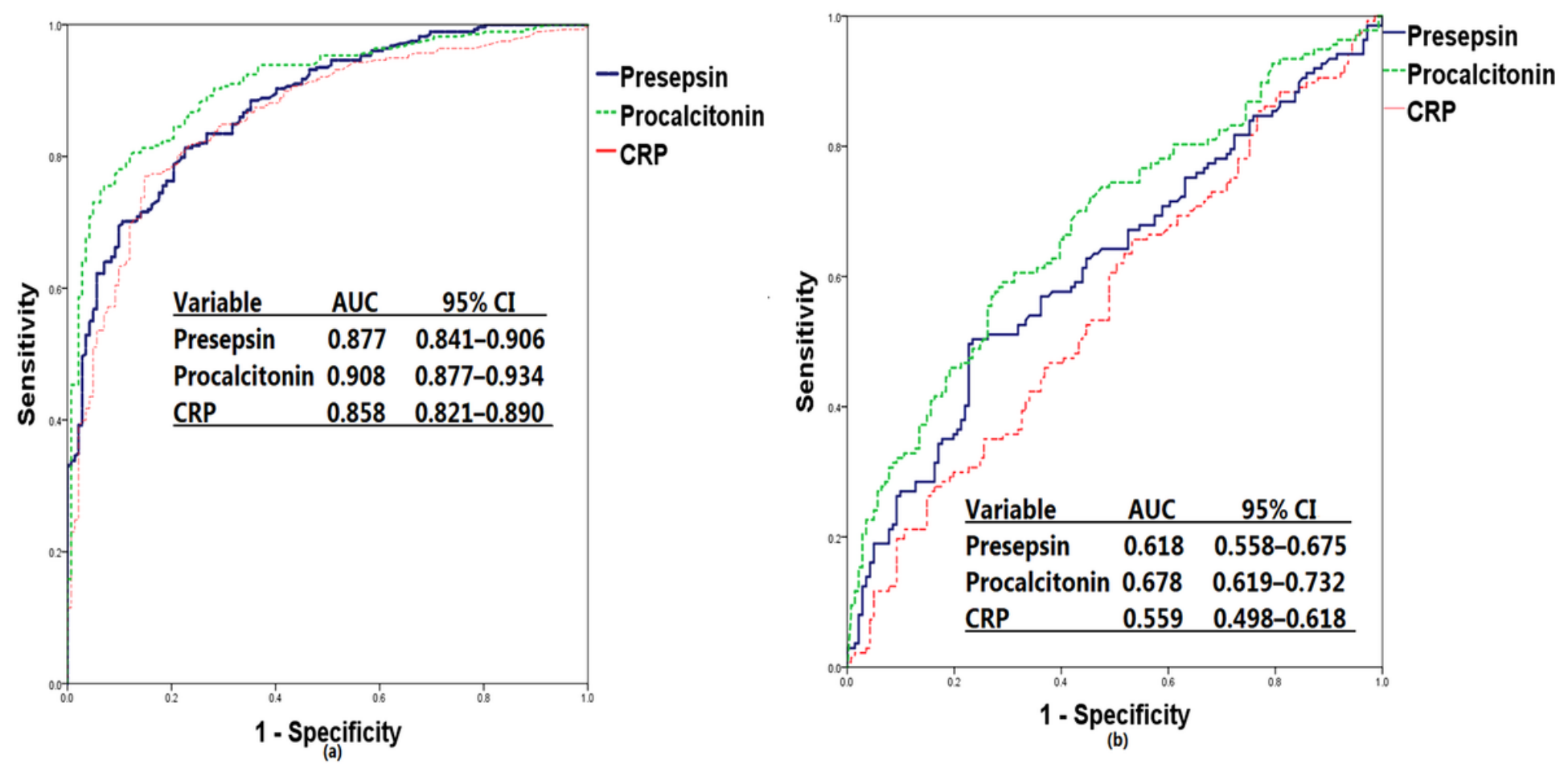

Figure 3

Receiver operating characteristic (ROC) curves of presepsin, procalcitonin, and CRP for discrimination of sepsis (including shock) from non-infectious organ failure (a) and for discrimination of septic shock from sepsis (b). 


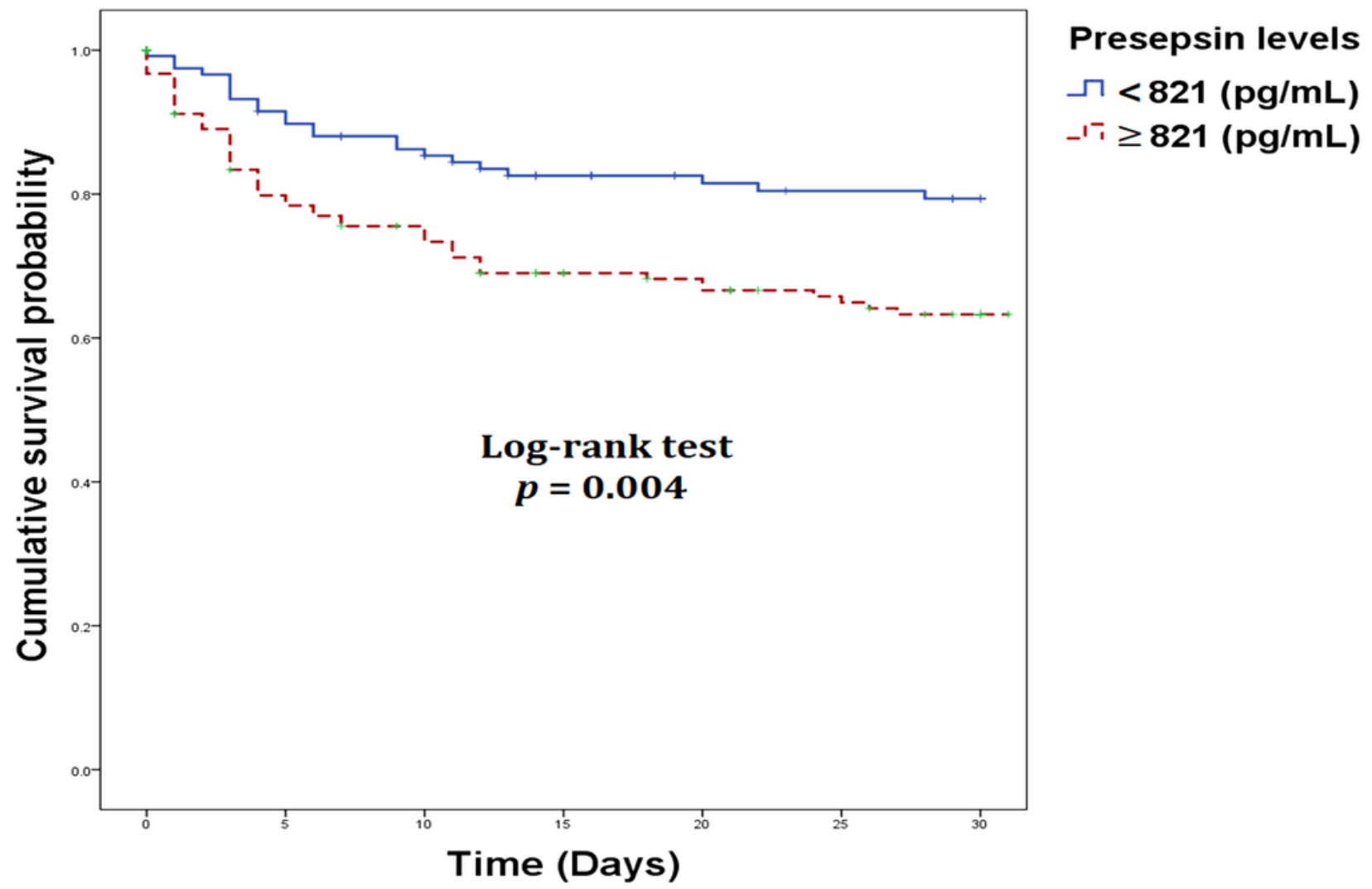

Figure 4

Kaplan-Meier survival curve analysis and log-rank test according to the optimal cut-off of presepsin for predicting 30-day mortality in patients with sepsis and septic shock. 